\title{
PYGMY SUNDEWS - PROPAGATION AND CULTIVATION
}

\section{GREG BOURKE • Australia • orders@captiveexotics.com}

Pygmy sundews (Drosera sections Bryastrum and Lamprolepis) are a rewarding group to cultivate. As the name suggests, these plants are small in stature with all species $3 \mathrm{~cm}$ in diameter or smaller and rarely reaching more than $5 \mathrm{~cm}$ in height. Despite their small size, pygmy sundews produce comparatively large flowers, often larger than the plant! They're also very colorful, coming in white, yellow, pink, metallic orange, red, and every color in between (Fig. 1). However, it's not just the small size that differentiates this group from other sundews. They produce large stipule buds during the hot, dry summer period when they are effectively dormant and they produce small vegetative buds called gemmae to assist with rapid reproduction in autumn.

Many of the 58 currently recognized species and a number of manmade and natural hybrids are easily grown in a variety of potting mixes. The soils of the south west of western Australia where these plants occur are incredibly complex with areas dating back well into the Precambrian era. As these have weathered, dozens of different substrates have been exposed. This has driven the diversification of the plant species including the sundews. In saying this, we can loosely group the soil types the pygmy sundews occur in. The sands comprised of silica, quartz, and a variety of mineral sands occur through the region. These are as varied as the species that occur on them and home to the greatest number of species. Laterite soils are also varied in composition and harbor a range of species. Peaty soils are less common and just a few species occur on them. Although the peat-based soils are least common, in pot culture they are considered the most successful. A 50/50 mix of clean silica or quartz

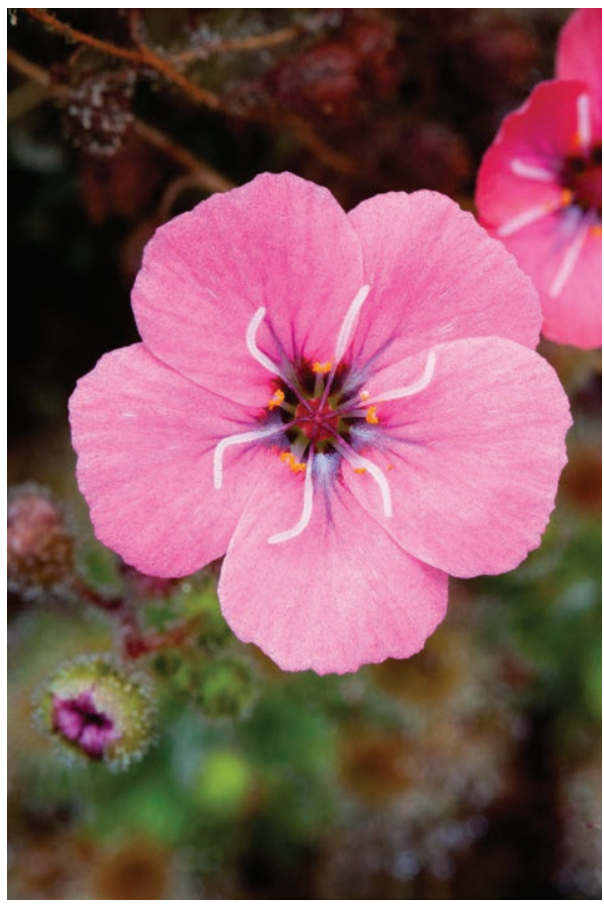

Figure 1: One of the many color forms of Drosera pulchella.

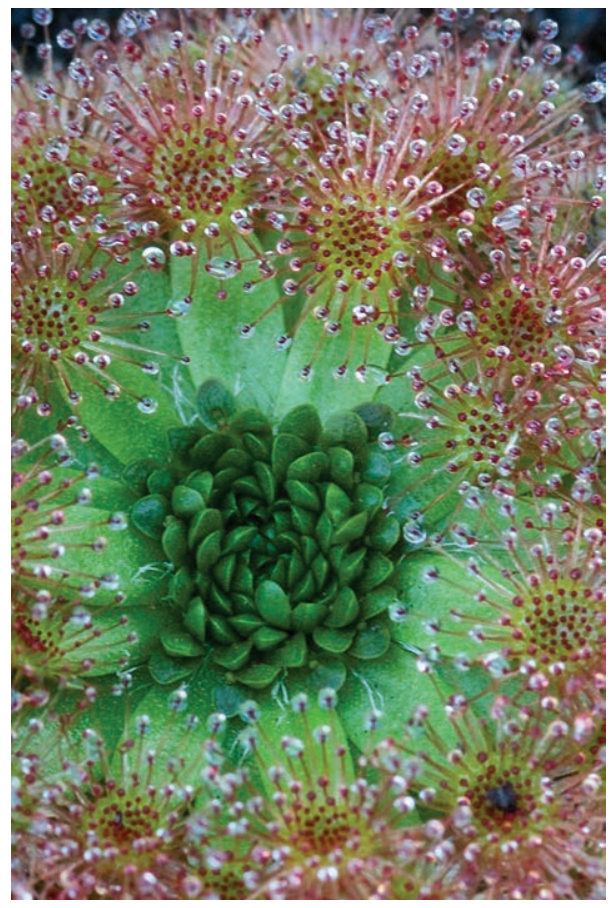

Figure 2: Drosera pulchella with ripe gemmae. 


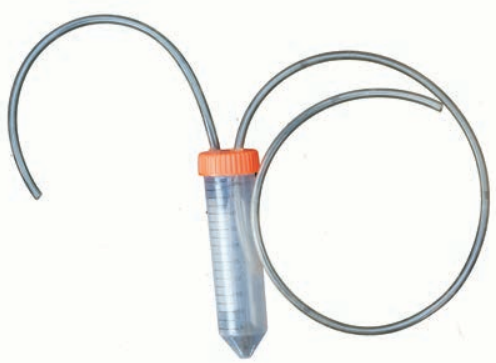

Figure 3: The completed gemmae collector.

sand (preferably round rather than angular) with peat works well. Perlite can also be added to the mix to reduce weight and cost. Pure peat can also be used but in my experience this is not ideal.

Pygmy sundews can be grown in tiny bonsai pots on sunny windowsills or large pots outdoors or in a glasshouse. In my opinion, they look their best when grown in a large pot in full sun as this is where they look most natural. Watering can be done from above or via a tray and they can be kept moist year round. In the wild, temperatures range from below freezing on Bluff Knoll where D. pulchella occurs at close

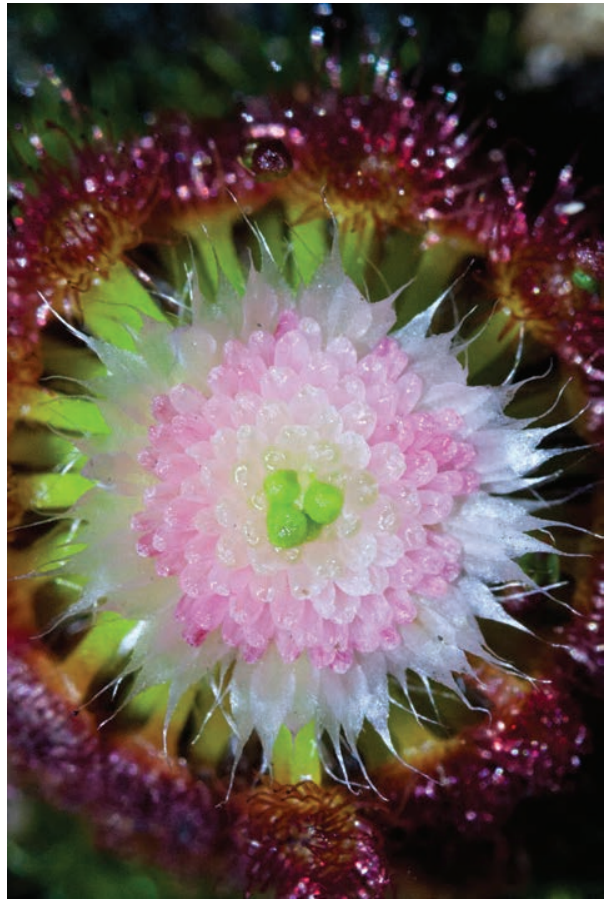

Figure 4: Drosera micrantha with gemmae removed.

to $1000 \mathrm{~m}$ asl to 40 degrees $\mathrm{C}$. in the height of summer. Replicating these temperatures in pot culture is dangerous and will almost certainly result in a reduced life span. Temperatures are best kept cool (5-15 degrees above freezing) in autumn and winter to induce good gemmae production and a little warmer in spring and summer.

Propagation can be achieved with seed, but as these plants produce few seeds, the easiest way is by collecting and spreading gemmae (Fig. 2). The clonal gemmae allow plants to rapidly reproduce in autumn. A single plant can produce almost 200 gemmae in a single season, and these can mature to flowering in as little as 3 months (Pers. obs.).

Collecting the gemmae can be done several different ways, but I have found that using an aspirator is by far the easiest way. An aspirator can be made at home using any airtight plastic jar with lid, 60 $\mathrm{cm}$ of clear plastic flexible tube (6 $\mathrm{mm}$ fishtank air hose is perfect), and a small piece of fine gauze (stockings are perfect). For my gemmae collector, I used a $50 \mathrm{ml}$ plastic test tube. In the lid I drilled two holes, one drill size smaller than the flexible tube. I cut the flexible tube into two lengths, one 20 $\mathrm{cm}$ long and the other $40 \mathrm{~cm}$. The shorter length is pushed through the hole in the test tube lid just 2 $\mathrm{cm}$ inside. Over the end that will end up inside the test tube, I tied a small piece of stocking. This is critical as it prevents any particles including gemmae from entering your lungs! The second, longer piece of flexible tube is pushed through the lid so it will end up $2 / 3$ of the way down the tube. Now, simply screw the lid on the test tube and you are ready to suck off your first pygmy sundew gemmae (Fig. 3). With the end of the short tube in your mouth and the end of the long tube in your hand, you can simply suck the gemmae off your plants without any damage to the plant or the gemmae (Fig. 4). Try to avoid touching the sticky leaves as this will get inside the flexible tube and gemmae will become stuck. 

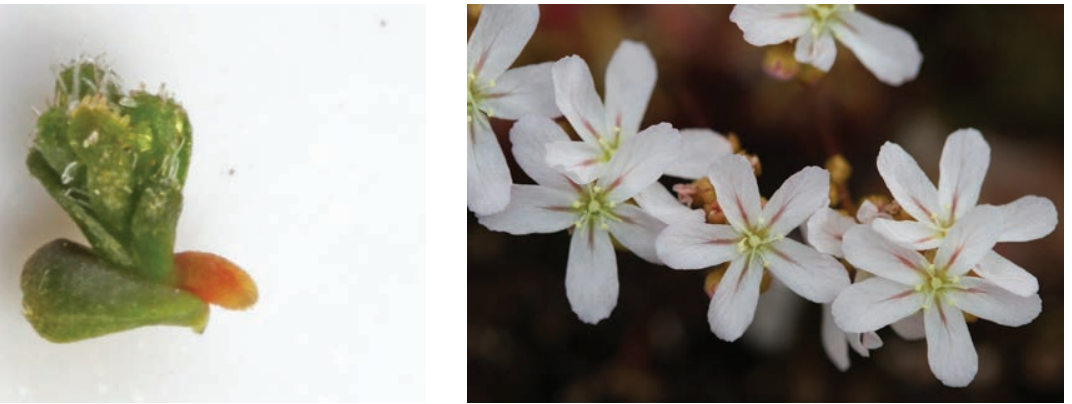

Figure 5: Sprouting gemma of Drosera

Figure 6: The rare Drosera oreopodion. barbigera.

Once the gemmae is collected, it can be stored in a refrigerator for up to three weeks, but is best sown fresh on the surface of wet media (Fig. 5). Keep freshly sown gemmae damp to wet until plants are well developed. I usually mist from above regularly for the first month.

Generally plants flower in spring and summer although I have had plants in flower year round. Flowers of different species also generally open on the same day triggered by bright light. This is when a large pot with dozens of plants is a stunning sight (Fig. 6). Very few seeds are produced by pygmy sundews and given the ease of production by gemmae, not really worth collecting as they can be challenging to germinate.

Pygmy sundews are in cultivation around the world and many of the 58 currently recognized species and a number of natural and manmade hybrids are available. If you get the opportunity to grow these delightful little sundews give them a go. I'm sure you will not be disappointed.

\section{References:}

D’Amato, P. 2013. The Savage Garden. Ten Speed Press, New York.

Lowrie, A. 2014. Carnivorous Plants of Australia Magnum Opus. Redfern Natural History Productions, Poole, England.

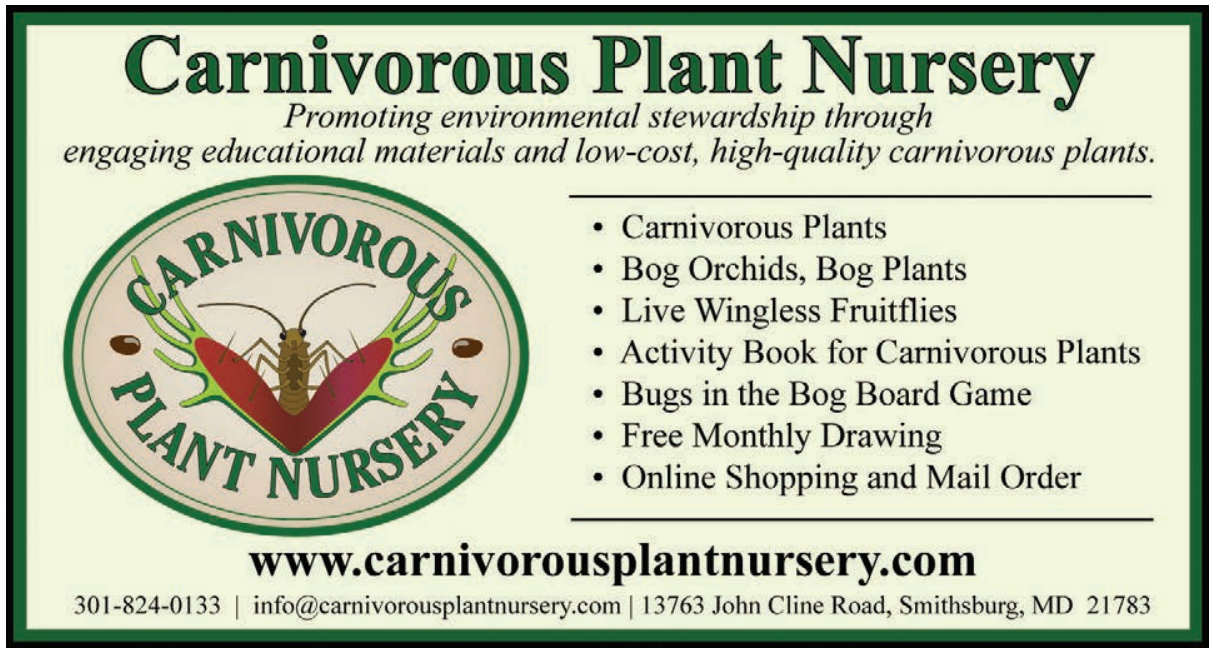

